$$
\begin{gathered}
\text { 도시림의 방문회수와 체류시간이 } \\
\text { 주관적 웰빙에 미치는 영향 } \\
\text { - 서울시를 중심으로 - } \\
\text { 홍성권 }{ }^{*} \cdot \text { 김종진 }^{*} \text { - 김주미 }
\end{gathered}
$$

"건국대학교 산림조경학과 · "건국대학교 대학원 환경과학과

\title{
Effects of the Number of Visits and Length of Stay in Urban Forests on Subjective Well-Being - A Case Study of Seoul -
}

\author{
Hong, Sung-Kwon ${ }^{*} \cdot \mathrm{Kim}$, Jong $\mathrm{Jin}^{*} \cdot \mathrm{Kim}, \mathrm{Ju} \mathrm{Mi}^{* *}$ \\ "Dept. of Forestry and Landscape Architecture, Konkuk University \\ "Dept. of Environmental Science, Graduate School, Konkuk University
}

\begin{abstract}
The purpose of this study is to investigate if subjective well-being could be improved by visiting urban forests near residential areas. Because visiting an urban forest is not an intense positive experience, this research is focused on frequency of affective experience rather than intensity. The independent variables are number of visits and length of stay. The dependent variables are positive affect, negative affect, and life satisfaction. A polling agency was employed to select 600 respondents by quota sampling, and data was collected by online survey. The results of ANOVA showed that there was no interaction between the number of visits and length of stay. Regardless of the number of visits, the subjective well-being of visitors of urban forests was enhanced: (a) positive affect of respondents who had visited in the past 2 weeks was increased while negative affect was decreased, and (b) life satisfaction for those who had visited at least 1 time per month was enhanced among usual visitors. The stay of length, however, had little effect on the increase or decrease of these three variables. The results of this study support the existing theory that one could reset their genetically determined happiness set point to a higher level by participating in intentional activities such as visiting urban forests that offer ways to achieve long-lasting changes in well-being. This means that it would be a valuable government investment to construct and maintain urban forests for improving citizens' welfare. A few comments were suggested regarding data collection and inclusion of influencing variables to make future subjective well-being studies more reliable.
\end{abstract}

Key Words: Positive Affect, Negative Affect, Life Satisfaction, Pleasant Experience

\footnotetext{
† : 본 연구는 산림청(한국임업진흥원) 산림과학기술 연구개발사업(FTIS 2017043B10-1819-BB01)’의 지원에 의하여 이루어진 것입니다.

${ }^{+}$: 이 논문은 2018학년도 건국대학교의 연구년교원 지원에 의하여 연구되었음.
}

Corresponding author: Jong Jin Kim, Dept. of Forestry and Landscape Architecture, Konkuk University, Seoul 05029, Korea, Tel.: +82-2-450-3737, E-mail: jjkimm@konkuk.ac.kr 


\section{국문초록}

본 연구는 생활권 도시림의 방문이 시민들의 주관적 웰 빙의 향상에 기여하는지를 검토하였다. 도시림 방문은 강한 경험이 아니기 때문에 강도 대신 빈도에 해당하는 방문회수와 체류시간을 독립변수로 사용하였으며, 종속변수는 긍정적 감정, 부정적 감정 및 삶의 만족도이었다. 서울시민을 대상으로 여론조사기관이 온라인 설문으로 수집한 600 매의 자료를 분산분석한 결과, (a) 도시림의 방문회수와 체류시간 간에는 상호작용 효과가 없었으며, (b) 방문회수와 상관없이 최근 2 주간 도시림을 방문한 사람들은 방문하지 않는 사람들보다 긍정적 감정이 높았으며 부정적 감정은 낮았고, 평소에 한 달에 1 번 이상 도시림을 방문한 사람들은 미방문자들보다 삶의 만족도가 높았지만, (C) 방문자들의 체류시간은 긍정적 감정, 부정적 감정 및 삶의 만족도 모두에 영향을 주지 못하였다. 결과적으로, 도시림 방문이란 의도적 활동이 유전적으로 결정된 주관적 웰빙 수준을 변화시킨다는 기존 이론을 확인함으로써, 도시림의 확대와 유지관리는 시민들의 복지향상을 위한 정부의 의미 있는 투자라는 것이 밝혀졌다. 보다 신뢰성 높은 추후연구를 위해 응답자 집단의 선정과 영향변수들의 중요성을 고찰하였다.

주제어: 긍정적 감정, 부정적 감정, 삶의 만족도, 즐거운 경험

\section{I. 서론}

현재 우리 사회는 과거 일 중심의 가치기준이 점차 쇠퇴하고 여가중시, 개인과 가족중심, 개성존중의 생활태도로 빠르게 변 하고 있다(Gyeonggi Research Institute, 2005). 2016년 국민들 의 평일 및 휴일의 평균 여가시간은 각각 3.1 시간과 5.0 시간이 었으며, 여가시간이 충분하다고 응답한 사람은 각각 $53.3 \%$ 와 66.9\%이었다(Ministry of Cultures, Sports and Tourism, 2016). 국내의 한 온라인 취업포털이 직장인 2,410명을 대상으로 조사 한 결과 (www.saramin.co.kr)에서는 응답자의 $78.2 \%$ 가 휴일근 무로 인한 실질임금 상승보다 휴일 근로시간 감소로 얻는 삶 의 여유가 더 좋다고 하였다. 복수응답이기는 하지만 응답자의 $63 \%$ 는 돈보다 삶의 질이 더 중요하다는 것이 이유이었다. 이 러한 결과들은 주 5 일 근무제가 정착되면서 과거보다 여가시간 이 늘어났으며, 삶의 질에 대한 관심이 높아져, 손쉽고 갈 수 있 는 곳에서 저렴한 가격으로 여가를 보내려는 수요가 증가하고 있다는 것을 의미한다. 앞으로도 이런 현상은 지속될 것이어서 주거지 근처에 있는 여가장소의 중요성은 높아질 것이다(Hong et al., 2007). 실제로, 국민들이 가장 많이 이용한 여가공간은 아파트 내/집 주변의 공터와 생활권 내의 공원이었으며, 희 망하는 곳은 산으로 나타나(Ministry of Cultures, Sports and Tourism, 2016), 도시림은 급증하는 여가수요를 충족시킬 수 있는 현실적 대안으로 주목받고 있다.

전국의 도시림은 도시면적의 $49 \%$ 로 높은 편이지만, 시민들 이 별도의 시간과 비용에 대한 부담 없이 실생활에서 쉽게 이 용할 수 있는 생활권 도시림은 전체 도시림 면적의 $3.7 \%$ 에 불 과하다(Korea Forest Service, 2016). 생활권 도시림이 시민들 에게 중요한 이유는 시간부족과 경제적 부담이 여가생활 불만
족의 가장 큰 원인이기 때문이다(Ministry of Cultures, Sports and Tourism, 2016). 시민들이 가장 중요하다고 생각하는 도시 림 역시 도시공원(48.4\%)과 거주지 주변 야산(41.3\%)으로 나 타났다(Byun et al., 2003). 또, 다른 이유는 여가활동의 목적이 대부분 행복, 즉 주관적 웰빙 (subjective well-being) 과 관련되 어 있기 때문이다. 대다수의 국민들이 '개인의 즐거움을 위해 (37.1\%)', '마음의 안정과 휴식을 위해( $16.9 \%)$ ', '스트레스 해소 를 위해(14.0\%)', '건강을 위해(10.3\%)' 여가활동을 하는 것으 로 나타났으며, $88.6 \%$ 가 여가활동을 삶의 필수적인 요건으로 생각하며, $91.7 \%$ 는 여가활동이 자신의 삶에 긍정적인 영향을 끼친다고 평가하였다(Ministry of Cultures, Sports and Tourism, 2016). 이러한 국민들의 여가수요에 맞추어 중앙정부와 지자체 도 생활권 도시림의 확장에 노력해 왔다. 1 인당 생활권 도시림 면적은 2013년도에 $8.32 \mathrm{~m}^{2}$ 이었지만, 2015년에는 $9.91 \mathrm{~m}^{2}$ 로 증가 해 세계보건기구가 권장하는 최소기준인 1 인당 $9 \mathrm{~m}^{2}$ 보다 높아 졌다(Korea Forest Service, 2014; 2016). 아직은 세계 주요 도 시인 파리 $\left(13 \mathrm{~m}^{2} /\right.$ 인), 뉴욕 $\left(23 \mathrm{~m}^{2} /\right.$ 인 $)$ 에 못 미치는 수준이지만, 전체 인구의 약 $90 \%$ 가 도시에 거주한다는 점을 고려하면 생활 권 도시림은 미래 시민들의 여가수요를 충족시키며, 주관적 웰 빙을 증진시키는데 기여할 수 있는 잠재력 높은 자원이다.

도시림을 이용하면 방문자들의 주관적 웰빙이 높아질 수 있 는 가능성은 기존연구를 통해 확인되고 있다. Lyubomirsky et al.(2005a)은 사람들의 노력에 좌우되는 의도적 활동이 유전적 으로 결정된 주관적 웰빙 수준을 변화시킬 수 있으며, 변화된 수준은 장기적으로 지속될 수 있다고 주장하였다. 또한, 즐거운 경험이 주관적 웰빙의 향상에 영향을 주는 것으로 알려져 있지 만, 시민들의 보편적 여가공간인 도시림에서의 여가활동이 주 관적 웰빙에 미치는 영향에 관한 연구는 아직 미미한 수준이다. 
이에 본 연구는 생활권 도시림의 방문이란 즐거운 경험이 주관 적 웰빙의 항상에 기여하는지를 검증하고자 한다. 구체적으로, 도시림 방문은 강한 경험이 아니기 때문에 방문빈도에 초점을 맞추었으며, 서울시를 대상으로 이곳의 방문빈도가 주관적 웰 빙의 향상에 긍정적 영향을 준다는 점을 밝혀 생활권 도시림이 필수 도시기반시설이란 점을 확인하고자 한다.

\section{II. 문헌연구}

\section{1. 도시림의 편익}

도시림은 다양한 편익을 준다는 것이 기존연구를 통해 밝혀 지고 있다. Tyrväinen et al.(2005)은 도시림이 사회적, 미적/건 축적, 기후 및 물리적, 생태적 및 경제적 편익을 주며, Kwon et al.(2004)은 환경적, 건강적, 경제적, 사회 · 심리적 편익을 주는 것으로 보고하였지만, 그 내용은 크게 다르지 않다. 이런 도시 림의 순기능으로 인해 국내에서도 도시림의 생태적 특성과 변 화, 환경적 편익 그리고 이용에 관한 연구들이 다수 수행되었 다. 그 중에서 도시림의 물리적, 생태적 또는 환경적 편익에 해당하는 연구들이 활발히 수행되었다. 탄소흡수 및 저장 (Jo et al., 2016), 미기후 개선(Jo and Ahn, 2006), 대기정화(Korea Forest Research Institute, 2010), 우수차집 및 저류(Xiao et al., 1998), 생물다양성의 증가(Cha and Park, 1999), 소음저감효과 (Ministry of Environment, 2003) 등이 그것이다. 미적 및 경제 적 편익에 관한 연구로는 녹지경관의 선호도(Lien and Buhyoff, 1986), 식재형태별 선호도(Yoo et al., 2007) 및 경제가치 추정 (Hong et al., 2010) 등 상대적으로 소수가 진행되었다. 사회적/ 심리적 편익에 관한 연구들은 이용실태와 관리방안에 집중되 었다. 이용촉진 방안(Gyeonggi Research Institute, 2005), 이용 특성과 관리방안(Shin et al., 2010) 등이 예이다.

건강적 편익은 사회적 편익의 하나로(Tyrväinen et al., 2005), 우리나라 도시림 이용자들이 가장 많이 받고 있는 편익이지만 (Kwon et al., 2004) 이 부문의 연구는 매우 부진하다. 두 연구 는 도시림이 주는 건강적 편익을 스트레스의 완화로 한정하고 있지만, 환자들이 녹지를 보는 것만으로도 건강 회복에 도움 이 된다는 Ulich(1984)의 연구 이후 주거지 내 녹지가 주는 여 러 가지 긍정적 효과들을 검증하기 위한 연구들이 수행되었다. Grahn and Stigsdotter(2003)는 녹지를 자주 방문할수록 스트 레스로 인한 질병이 적어진다고 하였으며, Lee et al.(2011)은 산림지역을 3 일 동안 15 분간 감상하는 것만으로도 도시에 체 류하는 것보다 대뇌의 활성화, 심박 및 혈압의 정상화, 스트레 스 저항 호르몬의 분비촉진 등 긍정적인 생리적 효과가 있을 뿐 아니라, 안정감 증가, 원기회복, 스트레스 저하와 같이 긍정 적 감정은 상승하며 부정적 감정은 억제되는 효과가 있다는 것 을 발견하였다. 또한, 생활녹지는 주민들이 자신의 주관적 건강
상태를 좋게 평가하게 하며(Maas et al., 2006), 노인들의 수명 에도 긍정적 역할을 주는 것으로 알려져 있다(Takano et al., 2002). 그러나 국내에서는 도시림 방문이 주관적 웰빙에 주는 영향에 관한 연구는 거의 이루어지지 않았다.

\section{2. 주관적 웰빙}

동서양을 막론하고 과거부터 사람들이 추구하는 가장 중요 한 목표의 하나는 행복이지만, 이를 학문적 연구를 시작한 것은 1970년대이다(Diener, 1984). 학문분야에 따라서는 행복(happiness), 주관적 웰빙, 삶의 질, 삶의 만족도(life satisfaction)를 유사한 용어로 사용하고 있다(Dolnicar et al., 2013). 그러나 행 복은 기쁨(joy)이나 만족을 의미하기 단어이어서 현재는 과학 적 용어인 주관적 웰빙을 사용하는 추세이다. 주관적 웰빙의 개 념화도 다양하지만 현재는 주관적 웰빙이 긍정적 감정(positive affect), 부정적 감정(negative affect) 및 삶의 만족도로 구성 된다는 것에 동의하고 있다(Diener, 2000). 즉, 자신의 삶에 대 해 만족하며, 긍정적 감정을 부정적 감정보다 많이 경험하는 사 람일수록 주관적 웰빙이 높다는 것이다. 이 세 가지 요소들은 서로 상관성이 있지만 주관적 웰빙을 종합적으로 파악하기 위 해서는 각각을 측정해야 사람들의 전체적인 수준을 평가할 수 있다(Diener and Seligman, 2004). 긍정적 감정과 부정적 감정 은 감정적 요소이어서 특정 사건의 좋고 나쁨에 대한 즉각적 평가인 반면, 삶의 만족도는 인지적 요소로써 “자신이 정한 기 준에 따라 평가한 전반적인 삶의 질(Shin and Johnson, 1978, p.487)"로 정의되고, 인생의 의미와 목적과 같은 요소들도 포함 된다. 감정적 요소는 변동성이 크며 단기적이지만 삶의 만족도 는 상대적으로 안정적이며, 중 - 장기적인 특성이 있다(Eid and Diener, 2004).

\section{1) 긍정적 감정의 효과}

긍정적 감정을 부정적 감정보다 많이 경험한 사람들은 경제 적으로 성공적이며, 다른 사람들과 우호적 관계를 형성하고, 육 체적 - 정신적 건강을 유지하며 장수한다는 것이 메타분석을 통 해 확인되었다(Lyubomirsky et al., 2005b). 이는 사람들이 바 람직한 결과를 얻으면 긍정적 감정이 생길 뿐만 아니라, 긍정 적 감정이 성공적 결과를 유도해 낸다는 것을 의미한다. 긍정 적 감정이란 사람들이 기쁨, 흥미, 자신감과 같은 긍정적 정서 를 얼마나 많이 경험하는지를, 부정적 감정이란 공포, 슬픔, 분 노와 같은 부정적 정서를 얼마나 많이 경험하는가이다(Snyder and Lopez, 2002). 긍정적 감정과 바람직한 결과의 발생 간 의 상호관계를 설명하는 이론들도 존재한다. 확장과 수립이론 (broaden-and-build theory)에 의하면, 긍정적 정서를 많이 경 험하면 이전에 비해 새롭고도 폭넓은 생각을 하게 되어 일상에 서 특정 상황이 발생할 때 이에 대처할 수 있는 심적, 행동대안 
의 수가 증가한다. 이런 새로운 경험들이 모여져 다른 상황에 도 대처할 수 있는 그 사람의 지속적인 자원(물리적, 지적, 사 회적 및 심리적)이 된다. 예를 들어 호기심은 전문지식으로 발 전할 수 있으며, 다른 사람과의 오락이 그들과 평생 지속되 는 관계로 발전될 수 있다. 증가한 자원은 다시 긍정인 주관적 웰빙의 감정적 요소를 향상시키는 선순환을 한다(Fredrickson, 1998). Hedonic contingent model(Wegener and Petty, 1994) 에서는 기분이 좋은 사람은 긍정적 결과가 예상되어 좋은 기분 이 유지되는 활동을 적극적으로 찾는다고 주장하고 있다. 두 이론을 종합하면, 즐거운 경험을 많이 한 사람은 훗날 닥칠 상 황에 대처할 수 있는 자원이 많아져 대처능력이 향상된다. 이 런 사람들은 즐거운 기분을 유지하기 위해 긍정적 결과가 예상 되는 일들을 적극적으로 찾는다. 의도적으로 찾은 즐거운 일들 은 긍정적인 기분을 상승시키거나 유지시키는데 도움을 주어 결국 이런 사람들은 행복하게 된다.

\section{2) 긍정적 감정의 빈도와 강도}

긍정적 감정과 부정적 감정 간의 독립성 여부는 오랜 논쟁거 리이었지만, 둘 간의 상관성은 감정적 요소의 영향변수인 빈 도와 강도의 역할에 따라 달라진다는 것이 확인되었다(Diener et al., 1985a). 긍정적 감정과 부정적 감정은 동시에 경험할 수 없어 단기간이라면 긍정적 감정을 많이 경험하는 사람일수록 부정적 감정을 적게 경험한다. 몇 주 이상인 경우라면 강한 긍 정적 감정을 경험한 사람들의 대부분은 부정적 감정도 강하 게 경험하기 마련이어서, 강도로 인한 효과를 제거하면 긍정적 감정과 부정적 감정 간의 상관성은 매우 낮아진다. 그러나 사 람들은 강한 긍정적 감정을 경험할 수 있는 기회는 많지 않으 며, 소소한 즐거움을 자주 느끼기 때문에(Diener and Seligman, 2004 ) 주관적 웰빙은 긍정적 감정의 강도가 아닌 빈도에 의 해 영향을 받게 된다(Diener et al., 1991). 이런 주장은 전망이 론(Kahneman and Tversky, 1979)과 쾌락적응현상(hedonic adaptation)(Frederick and Loewenstein, 1999)으로도 설명된 다. 즉, 즐거움이란 경험시점부터 감소하기 시작해 시간이 지 날수록 감소속도가 빨라져 결국은 이전 상태로 돌아가기 때문 에 강한 즐거운 경험보다는 여러 번의 작은 즐거운 경험이 사 람들의 전체적인 주관적 웰빙의 증진에 도움이 된다(Dunn et al., 2011). Diener et al.(1991) 은 강도보다 빈도를 사용해야 하 는 이유를 다음과 같이 제시하였다. 첫째, 사람들은 긍정적 감 정을 경험한 빈도를 쉽게 기억하며, 회상해낼 수 있어 신뢰성 있는 측정이 가능하지만, 강도는 사람들마다 평가가 주관적이 어서 정확한 측정이 어려울 뿐 아니라, 다른 사람들과 비교하 기도 어렵다. 둘째, 빈번한 긍정적 감정의 경험은 사람들이 주 관적 웰빙을 향상시키는 필요충분조건이지만, 강도는 필요조건 도 충분조건도 아니다. 셋째, 강한 긍정적 감정을 경험한 사람
이 강한 부정적 감정을 경험할 경우가 많다. 강한 긍정적 감정 은 훗날 일어날 부정적 감정의 경험을 보다 부정적으로 느끼게 하는 것이 한 가지 이유이다.

\section{3) 삶의 만족도}

감정적 요소는 사람들이 기분 좋게 보내는 시간이 어느 정도 인지를 나타낸다면, 삶의 만족도는 자신의 삶이 얼마나 바라던 대로인지를 의미한다. 삶의 만족도는 스스로 정한 기준 또는 다른 사람들과 비교해 자신의 상황을 평가하기 때문에 인지적 이며 종합적인 성격을 갖는다. 구체적으로, 자신의 중요 생활영 역에 대한 만족과 같이 언제라도 쉽게 사용할 수 있는 정보뿐 아니라, 평가 당시의 기분이나 정서를 포함해 평가하므로 감 정적 요인에 의해서도 일부 영향을 받는다(Pavot and Diener, 2008). 이로 인해 삶의 만족도에는 성격으로 인한 장기적 요소, 경험한 사건들로 인한 중기적 요소 그리고 평가 당시의 기분이 나 환경요인으로 인한 단기적 요소가 모두 포함되어(Yardley and Rice, 1991), 오랜 기간 동안 일정수준을 유지하는 것이 보 통이지만 어느 정도는 평가 당시의 기분이나 환경에 의해서 영 향을 받으며 감정적 요소와도 상관성이 있다.

\section{3. 주관적 웰빙과 도시림}

도시림이 시민들의 주관적 웰빙의 향상에 기여할 수 있는 근 거는 여러 이론들에서 제시되어 있다. 주관적 웰빙의 상향이론 (bottom-up theory)에 따르면, 주관적 웰빙은 사람들이 각 핵 심 생활영역에서 경험한 즐거움과 고통들을 합산한 후, 각 영 역의 중요성을 고려해 가중 평균해 결정된다. 여가와 레크리에 이션 영역은 전체 주관적 웰빙의 $6 \%$ 정도를 설명하지만 기존 연구들의 $2 / 3$ 정도가 여가와 레크리에이션을 핵심 생활영역에 포함시키고 있을 정도로 중요성을 인정하고 있다(Dolnicar et al., 2012). 도시림은 시민들이 쉽게 자주 방문할 수 있는 곳이 어서 작은 즐거움이 모여져 여가 및 레크리에이션 영역의 만 족도를 높일 수 있으며(Diener, 2009), 높아진 이 영역의 만족 은 결국 주관적 웰빙의 향상에 기여한다(Diener et al., 1991). Lyubomirsky et al.(2005a)은 기존 웰빙 관련 연구들을 종합해 행복이 유전적 요인(50\%), 의도적 활동( $40 \%)$, 환경요인(10\%) 으로 결정된다는 것을 발견한 후, 유전적으로 결정된 웰빙 수 준도 사람들의 의도적 활동으로 변화될 수 있다고 주장하였다. 환경(circumstantial)요인, 예를 들어 인구통계적 또는 지역적 요인은 대부분 자신의 의지와 상관없이 결정되며 생애를 통해 비교적 안정적이나 이 요인의 변화로 생긴 주관적 웰빙의 변화 는 단기적이다. 전체의 절반을 차지하는 유전적 요인은 사람들 의 노력으로 변화시킬 수 없는 부분이지만, 나머지 $40 \%$ 를 좌 우하는 의도적 활동(intentional activity)은 사람들이 일상생활 에서 행동하며, 생각할 수 있는 다양한 행동적, 인지적, 의지적 
(volitional) 활동을 포함한다. 예를 들어 정기적 운동과 같은 행 동적 활동, 현실 지향적으로 살고자 하는 인지적 활동, 자신의 목표달성을 위해 노력하는 의지적 활동이 여기에 포함된다. 도 시림의 방문이란 Lyubomirsky et al.(2005a)이 분류한 행동적 활동일 뿐 아니라, 동기 충족을 위한 의지적 활동이어서 사람 들의 장기적인 주관적 웰빙을 향상시킬 수 있는 훌륭한 수단이 다. 또한, 도시림 방문 중에 일어날 수 있는 행태들은 다양해 방문 시마다 새로운 경험을 할 수 있으며, 방문 후에는 즐거웠 던 경험을 다시 음미함으로써 그때의 감정을 재 경험할 수 있 어(Quoidbach et al., 2010), 증가한 주관적 웰빙 수준이 지속적 으로 유지될 가능성이 높다(Wegener and Petty, 1994)."

\section{III. 연구방법}

\section{1. 자료 수집}

자료는 경제성을 고려해 여론조사기관이 만 20 59세의 서 울시민 600 명을 쿼타샘플링하여 온라인 설문으로 수집하였다 (Table 1 참조). 사용한 쿼터는 지역(도심권, 동남권, 서남권, 서북권), 나이(20대, 30대, 40대, 50대) 및 성별이었고, 자료수 집 기간은 2017년 7월 31일 8월 8일이었다.

\section{2. 변수의 측정}

산림자원의 조성 및 관리에 관한 법률에서는 도시림을 "도 시에서 국민 보건 휴양·정서함양 및 체험활동 등을 위하여 조 성·관리하는 산림 및 수목”으로 정의하고 있다. 면지역과 자 연공원을 제외하고 있지만 실제로는 도시에 있는 대부분의 산 림, 식재지역, 도시공원과 녹지를 도시림으로 분류하고 있어, 시민들이 생각하는 도시림과는 거리가 먼 가로수, 벽면녹화지,

Table 1. Quota of respondents

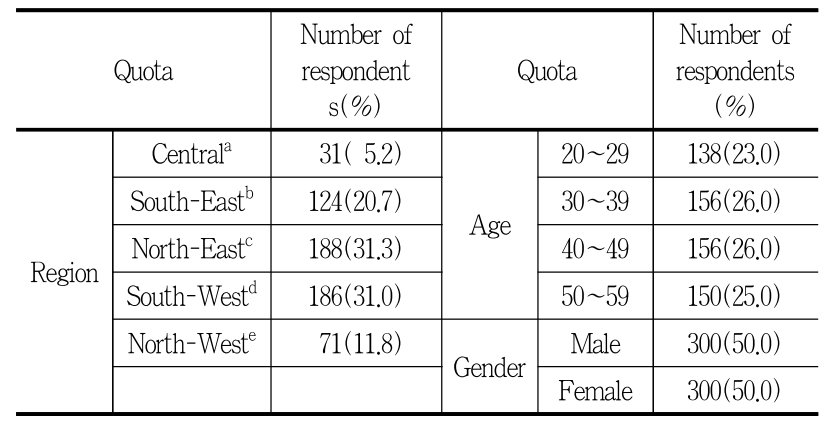

\footnotetext{
a: Jongno, Jung, Yongsan

b: Gangnam, Gangdong, Seocho, Songpa

c: Gangbuk, Gwangjin, Nowon, Dobong, Dongdaemun, Seongdong, Seongbuk, Jungnang

d: Gangseo, Gwanak, Guro, Geumcheon, Dongjak, Yangcheon, Yeongdeungpo

e: Mapo, Seodaemun, Eunpyeong
}

유원지 등도 포함되어 있다. 이런 이유로 본 연구는 생활권 도 시림을 "시민이 이용함에 있어 별도의 시간 및 비용에 대한 부담이 낮고, 실생활에서 쉽게 접근·활용할 수 있는 도시림 (Korea Forest Service, 2016)"으로 규정한 후 다음과 같이 분 석에 필요한 변수들을 조작화 하였다. 긍정적 감정과 부정적 감 정은 Scale of Positive and Negative Experience(SPANE)로 측정하였다(Diener et al., 2009). SPANE는 응답자의 광범위한 기분을 측정하는 척도로 일정기간 동안 경험했던 긍정적 및 부 정적 감정의 빈도를 각각 6 개 항목 5 점 척도로 측정하며, 국내 외를 통해 신뢰성과 타당성이 검증되었다(Hong et al, 2017). 경험기간은 고정된 것이 아니어서 본 연구는 최근 지난 2주 동 안으로 설정하였다. 응답자들의 총체적 삶의 만족도는 Satisfaction With Life Scale(SWLS)로 측정하였다(Diener et al., 1985b). 이 척도는 5개 항목 7점 척도로 구성되어 있으며, 국내 외 연구를 통해 신뢰성과 타당성이 검증되어 주관적 웰빙 연구 에 보편적으로 사용되고 있다. 즐거운 경험의 빈도란 회수와 지속시간을 의미하기 때문에, 본 연구는 이를 도시림의 방문회 수와 평균 체류시간으로 측정하였다.

사용한 척도인 SPANE와 SWLS의 타당성은 주성분 요 인분석의 결과를 배리맥스로 회전시켜 확인하였다. 예상대로 $\mathrm{SPANE}$ 는 긍정적 감정과 부정적 감정의 2개 요인으로, SWLS 는 단일차원으로 추출되었다. SPANE로 측정한 긍정적 감정과 부정적 감정은 각각 전체 분산의 $33.47 \%$ 와 $28.00 \%$ 를 설명하였 으며, SWLS는 $71.19 \%$ 를 설명하였다. 두 척도의 신뢰성을 Cronbach의 $a$ 값으로 검토한 결과, 긍정적 감정과 부정적 감정 을 측정하는 SPANE 문항들의 값은 각각 0.9269 와 0.8821 이었 으며, SWLS의 a값은 0.9289 이어서 판단의 기준치라 할 수 있 는 $0.7 \sim 0.8$ 보다 높았다(Table 2 참조).

\section{IV. 결과 및 고찰}

\section{1. 방문회수와 체류시간}

전체 응답자 600명 중 192명(32.0\%)이 평소에 생활권 도시 림(이하 ‘도시림'이라 한다.)을 1달에 1 3번 방문해 빈도가 가 장 높았다. 1 주일에 1 번 이상 방문한 사람은 148 명 $(24.6 \%)$ 이었 으며, 1 달에 1 번 이상 방문자는 340 명 $(56.6 \%), 1$ 년에 1 번 이상 방문자는 540 명 $(90 \%)$ 에 달하여 도시림은 서울시민의 대표적 인 여가장소라는 것이 밝혀졌다. 방문자들의 약 절반인 243명 (45.0\%)이 도시림에서 1 2시간을 체류하였으며, 3 시간 이상 의 체류자는 41 명 $(7.5 \%)$ 에 불과해 대부분은 3 시간 이내로 체 류하였다. 최근 2 주 동안으로 한정하면, 일주일에 1 2회 방문 한 사람이 135 명 $(22.5 \%)$ 으로 빈도가 가장 높았다. 이 기간 동 안 미방문자는 290 명(48.3\%)으로 평소 미방문자 비율인 $10 \%$ 보 
Table 2. Results of factor analysis and reliability test of measurement scales

\begin{tabular}{|c|c|c|c|c|}
\hline Variables & Item & F1 & F2 & Cronbach's a \\
\hline \multirow{6}{*}{$\begin{array}{l}\text { Positive } \\
\text { affect }^{a}\end{array}$} & Good & 0.8087 & -0.2407 & \multirow{6}{*}{0.9269} \\
\hline & Pleasant & 0.8110 & -0.1549 & \\
\hline & Happy & 0.8261 & -0.1710 & \\
\hline & Joyful & 0.8296 & -0.1968 & \\
\hline & Contended & 0.7475 & -0.1243 & \\
\hline & Positive & 0.7635 & -0.2567 & \\
\hline \multirow{6}{*}{$\begin{array}{l}\text { Negative } \\
\text { affect }^{3}\end{array}$} & $\mathrm{Bad}$ & -0.2016 & 0.7738 & \multirow{6}{*}{0.8821} \\
\hline & Unpleasant & -0.1349 & 0.7551 & \\
\hline & Sad & -0.1139 & 0.6442 & \\
\hline & Afraid & -0.2230 & 0.6341 & \\
\hline & Angry & -0.1318 & 0.7465 & \\
\hline & Negative & -0.2322 & 0.7647 & \\
\hline \multirow{5}{*}{$\begin{array}{l}\text { Life } \\
\text { satisfaction }^{b}\end{array}$} & In most ways my life is close to my ideal. & 0.8766 & & \multirow{5}{*}{0.9289} \\
\hline & The conditions of my life are excellent. & 0.8414 & & \\
\hline & I am satisfied with my life. & 0.8554 & & \\
\hline & So far I have gotten the important things I want in life. & 0.8308 & & \\
\hline & If I could live my life over, I would change almost nothing. & 0.8132 & & \\
\hline
\end{tabular}

\footnotetext{
a: Measured by SPANE
}

b: Measured by SWLS

다 매우 높았지만, 전반적으로 방문회수가 평소와 비슷한 이유 는 장마의 영향으로 보인다. 장마기간과 자료수집 기간이 중복 되어 평소에 도시림을 방문하던 사람들이 장마 후에 집중적으 로 이용한 것이다. 방문자들의 약 절반인 145 명(46.8\%)이 도 시림에서 1 2시간 체류하였으며, 그 다음으로 97 명 $(31.3 \%)$ 이 1 시간 이내로 체류하였다. 3 시간 이내의 체류자를 모두 합치 면 296명(95.5\%)으로 평소 방문자들의 비율과 유사하였다
(Table 3 참조). 복수응답이긴 하지만, 산책(22.2\%)이나 휴식 (19.1\%) 같이 가벼운 운동을 위해 도시림을 방문하는 응답자 가 전체의 $41.3 \%$ 이었으며, 운동/등산을 위해 방문한 사람이 $11.8 \%$ 이어서, 이 셋을 합치면 운동과 관련된 목적으로 방문하 는 응답자들이 전체의 절반이 넘는 $53.1 \%$ 이었다. 이 결과는 많 은 사람들이 핵심 생활영역의 하나인 건강을 위해 도시림을 방 문하였으며, 이로 인해 체류시간도 길지 않았다고 판단된다.

Table 3. Number of visits and length of stay

\begin{tabular}{|c|c|c|c|c|}
\hline & \multicolumn{2}{|c|}{ Usual use } & \multicolumn{2}{|c|}{ Recent two weeks } \\
\hline & Category & Respondents $(\%)$ & Category & Respondents $(\%)$ \\
\hline \multirow{7}{*}{$\begin{array}{l}\text { Number } \\
\text { of visits }\end{array}$} & Almost everyday & $12(2.0)$ & Almost everyday & $6(1.0)$ \\
\hline & 4 to 6 times/week & $23(3.8)$ & 5 to 6 times/week & $13(2.2)$ \\
\hline & 1 to 3 times/week & $113(18.8)$ & 3 to 4 times/week & $35(5.8)$ \\
\hline & 1 to 3 times/month & 192(32.0) & 1 to 2 times/week & $135(22.5)$ \\
\hline & 1 to 3 times/year & $159(26.5)$ & 1 time/2 weeks & $121(20.2)$ \\
\hline & 1 time/years & $41(6.8)$ & No visit & $290(48.3)$ \\
\hline & No visit & $60(10.0)$ & & \\
\hline \multirow{6}{*}{$\begin{array}{l}\text { Length } \\
\text { of stay }\end{array}$} & Within 1 hour & $128(23.7)$ & Within 1 hour & $97(31.3)$ \\
\hline & 1 to 2 hours & $243(45.0)$ & 1 to 2 hours & $145(46.8)$ \\
\hline & 2 to 3 hours & $128(23.7)$ & 2 to 3 hours & $54(17.4)$ \\
\hline & 3 to 4 hours & $33(6.1)$ & 3 to 4 hours & $10(3.2)$ \\
\hline & 4 to 5 hours & $4(0.7)$ & 4 to 5 hours & $1(0.3)$ \\
\hline & 5 hours or more & $4(0.7)$ & 5 hours or more & $3(1.0)$ \\
\hline
\end{tabular}

": Sixty and 290 non-visitors were excluded from usual use and recent 2 weeks, respectively 
실제로 응답자들은 도시림에서의 산책시간이 2시간 이상인 경 우가 1시간 이내 또는 1 2시간인 경우와 선호도에 차이가 없 었다.

\section{2. 도시림 방문과 주관적 웰빙}

\section{1) 집단의 세분}

도시림의 방문회수와 체류시간에 따른 주관적 웰빙의 차이 를 확인하기 위해 응답자들을 세분하였다(Table 4 참조). 도시 림을 어느 정도 방문해야 주관적 웰빙에 영향을 줄 것인지를 객관적으로 결정하는 것은 어려워 연구자의 주관으로 분류하 였으며, 체류시간은 분포를 고려해 결정하였다. 감정적 요소는 변동성이 크며 단기적이어서, 최근 2주 동안 1 주일에 1 2번 이 상 도시림을 방문한 응답자를 고이용집단, 2 주일에 1 번 방문한 응답자를 이용집단, 방문하지 않은 응답자를 미방문 집단으로 분류하였다. 체류시간의 경우에는 최근 2 주 동안 도시림에서 머물렀던 평균시간이 2시간 이상, 1 2시간, 1 시간 이내인 사람 들을 각각 장기체류집단, 중기체류집단, 단기체류집단으로 분 류하였으며, 미방문자 290 명은 집단분류에서 제외하였다.

삶의 만족도는 감정적 요소와 달리 안정적이며 중·장기적 이어서 평소에 도시림을 1 주일에 1 회 이상 방문한 응답자들은 고이용집단으로, 미방문자 60 명과 방문으로 인한 효과가 미미 할 것으로 예상되는 1년에 1 3회 이하 방문자들을 미 이용자 집단으로, 나머지 1달에 1 3번 방문한 응답자를 이용집단으로 분류하였다. 또한, 도시림에서 체류한 시간이 2시간 이상, 1 2 시간, 1 시간 이내인 사람들을 각각 장기체류집단, 중기체류집 단, 단기체류집단으로 분류하였다. 이때, 평소에도 도시림을 방 문한 적이 없는 미방문자 60 명은 집단분류에서 제외하였다.

2) 도시림 방문의 효과
도시림 방문효과 검증에 앞서, 미방문자들의 체류시간을 결 측치로 처리한 후 방문회수와 상호작용효과가 있는지를 확인 하였다. 최근 2주간 긍정적 감정과 부정적 감정을 종속변수로 분산분석한 결과, 도시림의 방문회수와 체류시간에는 상호작용 효과가 없었으며, 삶의 만족도 역시 평소 도시림의 방문회수와 체류시간 간의 상호작용에는 유의성이 없어(Table 5 참조), 방 문회수와 체류시간이 감정적 요소 및 삶의 만족도에 미치는 영 향력을 각각 분석하였다(Table 6 참조).

\section{(1) 감정적 요소}

$F$-검정 결과, 긍정적 감정은 최근 2주간 도시림의 방문회수 에 따라 차이가 있었지만 $(p<0.0001)$, 체류시간에는 차이가 없 었다 $(p=0.1183)$. 던컨검증 결과, 최근 2주간 도시림을 방문한 적이 있는 고이용집단과 이용집단의 긍정적 감정은 미이용집 단보다 높았지만, 고이용집단과 이용집단 간에는 평균차이가 없었다. 부정적 감정도 긍정적 감정의 결과와 유사하였다. 최근 2 주간 도시림의 방문회수에 따라 부정적 감정에는 차이가 있었 지만 $(p<0.0001)$ 체류시간에는 차이가 없었다 $(p=0.8833)$. 구체

Table 5. Interaction effects of number of visits and length of stay

\begin{tabular}{c|c|c|c|c|c|c}
\hline & Variables & d.f. & SS & MS & $F$-value & $p$-value \\
\hline \multirow{4}{*}{$\begin{array}{c}\text { Positive } \\
\text { affect }\end{array}$} & Number of visits & 1 & 1.3869 & 1.3869 & 3.20 & 0.0745 \\
\cline { 2 - 7 } & Length of stay & 2 & 1.8779 & 0.9390 & 2.17 & 0.1161 \\
\cline { 2 - 7 } & Interaction & 3 & 1.0758 & 0.5379 & 1.24 & 0.2902 \\
\hline \multirow{4}{*}{$\begin{array}{c}\text { Negative } \\
\text { affect }\end{array}$} & Number of visits & 1 & 0.6343 & 0.6343 & 1.39 & 0.2390 \\
\cline { 2 - 7 } & Length of stay & 2 & 0.1146 & 0.0573 & 0.13 & 0.8819 \\
\cline { 2 - 7 } & Interaction & 2 & 2.4516 & 1.2258 & 2.69 & 0.0695 \\
\hline \multirow{4}{*}{$\begin{array}{c}\text { Life } \\
\text { satisfaction }\end{array}$} & Number of visits & 2 & 19.9846 & 9.9923 & 6.22 & 0.0021 \\
\cline { 2 - 7 } & Length of stay & 2 & 0.4187 & 0.20934 & 0.13 & 0.8778 \\
\cline { 2 - 7 } & Interaction & 4 & 7.3050 & 1.8262 & 1.14 & 0.3380 \\
\hline
\end{tabular}

Table 4. Segmentation of respondents

\begin{tabular}{|c|c|c|c|c|c|c|c|}
\hline \multicolumn{5}{|c|}{ Positive affect and negative affect } & \multicolumn{3}{|c|}{ Life satisfaction } \\
\hline Variables & Group & Criteria & \multicolumn{2}{|c|}{ Respondents(\%) } & Criteria & \multicolumn{2}{|c|}{ Respondents $(\%)$} \\
\hline \multirow{3}{*}{$\begin{array}{l}\text { Number } \\
\text { of visits }\end{array}$} & Heavy user group & $\begin{array}{c}1 \sim 2 \text { or more times/ } \\
\text { week }\end{array}$ & $\begin{array}{c}189 \\
(31.5)\end{array}$ & \multirow{3}{*}{600} & 1 or more times/week & $\begin{array}{c}148 \\
(24.7)\end{array}$ & \multirow{3}{*}{600} \\
\hline & User group & 1 time/2 weeks & $\begin{array}{c}121 \\
(20.2)\end{array}$ & & $1 \sim 3$ times/month & $\begin{array}{c}192 \\
(32.0)\end{array}$ & \\
\hline & Non-user group & No visit & $\begin{array}{c}290 \\
(48.3)\end{array}$ & & $\begin{array}{c}1 \sim 3 \text { times/year, and } \\
\text { no visit }\end{array}$ & $\begin{array}{c}260 \\
(43.3)\end{array}$ & \\
\hline \multirow{3}{*}{$\begin{array}{l}\text { Length } \\
\text { of stay }\end{array}$} & Long stay group & 2 or more hours & $\begin{array}{c}68 \\
(21.9)\end{array}$ & \multirow{3}{*}{310} & 2 hours or more & $\begin{array}{c}169 \\
(31.3)\end{array}$ & \multirow{3}{*}{540} \\
\hline & Medium stay group & $1 \sim 2$ hours & $\begin{array}{c}145 \\
(46.8)\end{array}$ & & $1 \sim 2$ hours & $\begin{array}{c}243 \\
(45.0)\end{array}$ & \\
\hline & Short stay group & Within 1 hour & $\begin{array}{c}97 \\
(31.3)\end{array}$ & & Within 1 hour & $\begin{array}{c}128 \\
(23.7)\end{array}$ & \\
\hline
\end{tabular}

": Two hundred ninety and 60 non-visitors were excluded from affective component and life satisfaction, respectively 
Table 6. Effects of variables on positive affect, negative affect and life satisfaction and group mean differences

\begin{tabular}{|c|c|c|c|c|c|c|c|c|c|}
\hline & Variables & d.f. & SS & MS & $F$-value & $p$-value & Group & Sample size & Mean / Duncan test \\
\hline \multirow{4}{*}{$\begin{array}{l}\text { Positive } \\
\text { affect }\end{array}$} & \multirow{3}{*}{ Number of visits } & \multirow{3}{*}{2} & \multirow{3}{*}{13.6573} & \multirow{3}{*}{6.8286} & \multirow{3}{*}{15.17} & \multirow{3}{*}{$<0.0001$} & Heavy user & 189 & $3.4374 \mathrm{a}$ \\
\hline & & & & & & & User & 121 & $3.3003 \mathrm{a}$ \\
\hline & & & & & & & Non-user & 290 & $3.0977 \mathrm{~b}$ \\
\hline & Length of stay & 2 & 1.8779 & 0.9390 & 2.15 & 0.1183 & & & \\
\hline \multirow{4}{*}{$\begin{array}{l}\text { Negative } \\
\text { affect }\end{array}$} & \multirow{3}{*}{ Number of visits } & \multirow{3}{*}{2} & \multirow{3}{*}{10.3733} & \multirow{3}{*}{5.1867} & \multirow{3}{*}{11.52} & \multirow{3}{*}{$<0.0001$} & Non-user & 290 & $2.8017 \mathrm{a}$ \\
\hline & & & & & & & User & 121 & $2.6033 \mathrm{~b}$ \\
\hline & & & & & & & Heavy user & 189 & $2.5105 \mathrm{~b}$ \\
\hline & Length of stay & 2 & 0.1146 & 0.0573 & 0.12 & 0.8833 & & & \\
\hline \multirow{4}{*}{$\begin{array}{c}\text { Life } \\
\text { satisfaction }\end{array}$} & \multirow{3}{*}{ Number of visits } & \multirow{3}{*}{2} & \multirow{3}{*}{26.7335} & \multirow{3}{*}{13.3667} & \multirow{3}{*}{8.23} & \multirow{3}{*}{0.0003} & Heavy user & 148 & $3.9297 \mathrm{a}$ \\
\hline & & & & & & & User & 192 & $3.8365 \mathrm{a}$ \\
\hline & & & & & & & Non-user & 260 & $3.4569 \mathrm{~b}$ \\
\hline & Length of stay & 2 & 0.4187 & 0.2094 & 0.13 & 0.8801 & & & \\
\hline
\end{tabular}

적으로, 최근 2주간 도시림을 방문하지 않은 미이용집단의 부 정적 감정은 방문한 집단들보다 높았지만, 고이용집단과 이용 집단 간에는 차이는 없었다. 결과적으로 최근 2주간 도시림을 방문한 적이 있는 사람들은 회수와 상관없이 감정적 요소가 증 가하였으며, 부정적 감정은 감소하였다. 긍정적 감정과 부정적 감정의 결과가 유사한 이유는 짧은 기간 동안에 두 감정은 역 비례해 함께 증가하거나 감소하지 않지만 몇 주 이상의 긴 기 간 동안을 고려하면 상대적으로 독립적이어서 긍정적 감정이 증가할 때 부정적 감정은 감소할 수 있으며(Diener et al., 1985a), 고이용집단과 이용집단은 미방문집단보다 도시림 방문 으로 긍정적 감정을 느낀 회수가 부정적 감정보다 많아 나타난 결과로 해석된다(Diener et al. 1991). 레크리에이션 영역은 중요 생활영역의 하나이며, 사람들은 일상생활에서 대부분 약한 수준의 긍정적 경험을 하지만 이런 경험들이 모여져, 예 를 들어 도시림의 방문, 장기적인 주관적 웰빙이 증가한다 (Lyubomirsky et al., 2005). 이로 인해 이용집단과 고이용집단 은 레크리에이션 영역의 만족도가 추가로 증가했을 가능성이 높지만, 미방문집단의 경우에는 이런 기회가 거의 없어 두 집 단들보다 긍정적 감정이 낮은 것으로 보인다. 그러나 고이용집 단과 이용집단의 긍정적 감정에는 차이가 없었다. 그 이유는 레크리에이션 영역 이외의 다른 생활영역들에 대한 만족도가 주관적 웰빙의 증가에 더 큰 영향을 주지만(Dolnicar et al., 2012), 본 연구는 연구목적에 맞추어 레크리에이션 영역의 만 족도에 영향을 주는 도시림의 방문만을 변수로 사용했기 때문 이다. 응답자들은 일상생활에서 도시림 방문 이외에도 다양한 즐거운 경험을 하겠지만, 도시림 방문회수와 다른 생활영역에 서의 즐거운 경험의 회수를 구별해 측정하는 것은 어렵기 때문 에 방문회수의 증가로 인한 효과 차이를 밝힐 수 없었다. 도시 림 방문만을 변수로 사용했기 때문에, 부정적 감정의 경우, 역 시 응답자들이 다른 생활영역에서 어떤 경험을 했는지를 측정
할 수 없었다. 그러나 방문자의 경우에는 이곳에서의 즐거운 경험들이 그의 지속적 자원이 되어 새로운 상황에 대처할 수 있는 능력이 향상됨으로써 부정적 감정이 감소했으리란 예상 이 가능하다(Fredrickson, 1998).

(2) 삶의 만족도

삶의 만족도 역시 평소 도시림의 방문회수에 따라 차이가 있 었지만 $(p=0.0003)$ 체류시간에는 차이가 없었다 $(p=0.8801)$. 던 컨검증 결과, 평소에 도시림을 1 주에 1 번 이상 방문하는 고이 용집단과 1달에 1 3번 방문하는 이용집단은 미이용집단보다 삶의 만족도가 높았지만, 고이용집단과 이용집단 간에는 차이 는 없었다. 이론적으로 삶의 만족도와 감정적 요소는 다른 개 념이지만, 긍정적 감정과 부정적 감정은 인지적 평가의 결과로 생기기 때문에 삶의 만족도와 상관성이 있다. 차이는 감정적 요소가 현재 발생한 사건에 대한 즉각적 평가인 반면, 삶의 만 족도는 삶에 대한 포괄적 평가이다(Diener, 1994). 또한, 사람 들은 삶의 만족도를 평가할 때 당시의 기분에 좌우되기도 하며, 삶의 만족도가 사람들이 경험했던 긍정적 감정과 부정적 감정 의 양을 결정하기도 한다(Lucas et al., 1996). 이런 삶의 만족 도 특성으로 인해, 도시림 방문으로 증가한 긍정적 감정이 삶 의 만족도에 영향을 주어 평소에 도시림을 방문하는 사람들의 삶의 만족도가 높아졌을 것으로 해석된다. 그러나 감정적 요소 와 마찬가지 이유로, 도시림 방문회수가 삶의 만족도에 주는 효과 차이는 밝힐 수 없었다.

\section{V. 결론 및 시사점}

본 연구는 도시림의 방문이 주관적 웰빙의 항상에 긍정적 영 향을 주는지를 검토하기 위해 수행되었다. 이를 위하여 도시림 방문회수와 체류시간을 독립변수로, 주관적 웰빙의 구성개념인 
긍정적 감정, 부정적 감정 및 삶의 만족도를 종속변수로 사용 하였다. 서울시민을 대상으로 수집한 자료를 분산분석한 결과, 회수와 상관없이 도시림 방문은 사람들의 긍정적 감정, 부정적 감정과 삶의 만족도를 모두 향상시켰다. 구체적으로 (a) 최근 2주간 도시림을 방문한 적이 있는 사람들은 방문하지 않는 사 람들보다 긍정적 감정이 높았고 부정적 감정은 낮았지만, 방문 회수에 따른 긍정적 감정과 부정적 감정에는 차이가 없었고, (b) 평소 한 달에 1번 이상 도시림을 방문한 사람들은 미방문 자를 포함해 1년에 1 3회 이하로 방문하는 사람들보다 삶의 만족도가 높았지만, 감정적 요소의 경우와 마찬가지로 방문회 수 차이에 따른 삶의 만족도에는 차이가 없었다. 그러나 예상 과 달리 방문자들의 체류시간은 긍정적 감정, 부정적 감정 및 삶의 만족도 모두에 영향을 주지 못하였다.

이 같은 결과는 주관적 웰빙의 감정적 요소와 삶의 만족도의 특징에서 비롯된 것이다. 확장과 수립이론에 의하면, 사람들이 긍정적 감정을 많이 경험하면 순간의 생각과 행동 레퍼토리가 확장되어 결과적으로 이것은 다른 상황에도 대처할 수 있는 그 사람의 영속적 자원이 된다. 증가한 자원은 다시 긍정적 감정 을 향상시키는 선순환을 한다. 도시림의 방문과 같은 즐거운 경험이 긍정적 감정의 향상에 미치는 영향은 보통 단기적이 지만, 전통적으로 쾌락주의(hedonism)에서는 부정적 감정보다 긍정적 감정을 많이 경험하는 사람을 행복한 사람이라 보았다. 여기에 사람들은 증가한 웰빙 수준을 유지할 수 있는 활동을 의도적으로 찾는다는 점(Wegener and Petty, 1994), 그리고 일상생활에서의 소소한 즐거움들이 주관적 웰빙의 증가에 영 향을 준다는 점을 함께 고려해 본 연구의 결과를 해석하면 다 음과 같은 결론이 가능하다. 도시림 방문자들은 이곳에서 크지 는 않지만 즐거운 경험을 많이 하여 긍정적 감정이 높아졌을 뿐 아니라, 특정 상황에 대처할 수 있는 기술의 종류도 다양해 진다. 예를 들어 자원과 친구관계가 확장되어 미래의 다른 상 황에서도 유연하고 창의적으로 대처할 수 있는 능력이 높아졌 으며, 도시림에 가면 즐거운 일이 있다는 것을 알고 있어 이곳 을 지속적으로 방문함으로써 결국 주관적 웰빙의 감정적 요소 가 향상되었다는 것을 의미한다. 이 같은 결론은 도시림 방문 이 사람들의 긍정적 감정을 항상시키는데 기여할 뿐 아니라, 향상된 긍정적 감정을 유지하기 위한 수단의 하나로 사람들은 도시림을 다시 찾는 선순환이 이루어질 수 있다는 근거를 제시 한 것이어서, 왜 도시림이 존재해야 하는지 그 이유를 실증한 것으로 의미가 있다.

삶의 만족도는 인생의 질에 대한 전체적인 평가를 의미한다. 주관적 웰빙의 상향이론에 의하면, 사람들의 주관적 웰빙은 건강, 일, 여가, 가정, 사회성과 같은 핵심 생활영역들에 대한 만족도로 결정되는 것으로 알려져 있다. 사람들이 특정 생활영 역에 포함된 활동에 만족한다면 그 영역의 만족도가 증가하
며, 각 영역들의 만족도가 높아지면 상위개념인 주관적 웰빙도 높아진다. 실증연구에서도 삶의 만족도는 다수의 생활영역들 에 의해 결정되며(Loewe et al., 2014), 여가활동의 하나인 관 광이 삶의 만족도를 높인다고 보고하고 있다(Chen et al., 2013; Hong et al., 2017). 이 이론에 삶의 만족도가 감정적 요소보다 상대적으로 안정적이란 점을 고려해 결과를 해석하면, 도시림 을 자주 방문하면 이곳에서의 즐거운 경험들이 여가영역을 포 함해 다른 핵심 생활영역인 건강영역, 사회성 영역, 가정영역 등의 만족도를 지속적으로 향상시킴으로써 결국 전체적인 삶 의 만족도가 향상되었다고 볼 수 있다. 이러한 결과는 도시림 이 시민들의 웰빙 향상에 필요한 도시기반시설이어서 도시림 의 확대 및 유지관리는 복지차원에서 의미 있는 투자라는 것을 의미한다.

도시림의 체류시간은 방문회수와 달리 주관적 웰빙의 향상 에 영향을 주지 못하였다. 응답자들은 도시림에서 경험한 개개 의 사건을 긍정적 또는 부정적 감정으로 평가한 것이 아니라, 도시림 방문 자체를 하나의 경험으로 인식하고 있어 나타난 결 과로 보인다. 본 연구가 사용한 $\mathrm{SPANE}$ 는 응답자들이 일정기 간 동안 긍정적 감정과 부정적 감정을 얼마나 자주 느꼈는지를 평가하는 척도이다. 도시림에 오래 체류한 사람들은 그렇지 않 은 사람들보다 상대적으로 긍정적 또는 부정적 감정을 많이 경 험했을 가능성이 높지만, 응답자들은 도시림에서 느낀 두 감정 의 회수 차이로써 도시림 방문을 통합적으로 평가했기 때문에 체류시간은 유의성이 없었던 것으로 판단된다(Diener et al., 1991).

본 연구는 대표적인 도시 내 여가장소인 생활권 도시림이 시민들의 주관적 웰빙을 향상시킬 수 있는 현실적 수단이란 점을 실증하였다는데 의의가 있지만 추후연구에서는 다음과 같은 점이 보완되어야 할 것이다. 첫째, 본 연구는 탐색적 연구 (exploratory study)라 할 수 있으며, 경제적 이유로 응답자를 만 20 59세의 서울시민으로 한정하였다. 이로 인해 다른 도시 민들과 여가활동이 가장 필요한 계층이라 할 수 있는 60 대 이 상의 시민들이 자료에 포함되지 못하였다. 우리나라는 2021년 에 65 세 이상의 노인인구가 $20.22 \%$ 에 이르러 초고령사회로 진 입할 것이 예상되고 있다(http://kosis.kr/). 이들의 여가활동 목적은 다른 계층들과 다르다. 60 대와 70대에서는 '마음의 안 정과 휴식'과 '시간을 보내기'가 20 50대보다 높았지만, '스트 레스 해소'와 '가족과 함께 시간 보내기'는 낮았다(Ministry of Cultures, Sports and Tourism, 2016). 다른 도시민들을 포함시 키거나 60대 이상의 계층을 인구비율에 맞추어 응답자로 포함 시켜 도시림의 긍정적 기능을 확인하는 반복연구가 필요하다. 둘째, 사회심리학 분야에서의 연구를 통해 즐거운 경험의 빈도 가 주관적 웰빙을 증가시키는 것을 알려져 있지만, 이 연구들 역시 즐거운 경험의 지속시간은 측정이 어려워 대부분 회수를 변수로 사용하고 있다(Diener et al., 1985a; Lyubomirsky et 
al., 2005). 감정적 요소를 측정하는 대표적 척도인 SPANE 역 시 회수를 기준으로 개발된 척도이다. 이것이 지속시간에 유의 성이 없었던 주된 이유로 판단되므로 지속시간을 신뢰성 있게 측정할 수 있는 척도의 개발이 필요하다. 셋째, 주관적 웰빙에 영향을 미치는 중요한 변수를 포함하지 못하였다. 전통적으로 성격은 주관적 웰빙의 약 $50 \%$ 를 좌우하는 요소라고 여겨왔다. 이중, 신경증(neuroticism)은 삶의 만족도(Pavot et al., 1997) 와 감정적 요소에 부정적 영향을 주며(McCrae and John, 1992), 외향성 (extraversion)은 사람들이 긍정적 감정을 갖고 있 을 때 삶의 만족도에 향상에 영향을 준다(Rusting and Larsen, 1997). 또한 Oishi et al.(1999)은 자신의 가치와 부합하는 생활 영역의 만족이 전체적인 삶의 만족도 향상에 강한 영향을 준다 고 하였다. 즉, 같은 도시림을 방문해 동일한 활동을 한 사람들 이라도 여가와 레크리에이션 영역에 큰 가치를 부여하는 사람 은 경험이 만족스러울 경우, 그렇지 않은 사람보다 삶의 만족 도가 크게 높아진다. 휴가여행 후 중국인들은 "친구"와 "가족" 두 핵심 생활영역에 한해 만족이 증가했다는 것이 이런 가능성 을 보여주고 있다(Chen et al., 2013). 심도 있는 연구를 위해 제시한 변수들을 추가하는 것이 필요하다.

\section{References}

1. Byun, W., J. Lee, E. Seo, Y. Hong and T. Kim(2003) A study on urban resident's preference for developing urban recreational forest: The case study on Seoul · Daegu/Gyungbuk · Gyunggido. Korean Institute of Forest Recreation and Welfare 7(2): 19-25.

2. Cha, S. and C. Park(1999) Development of green network plan using bird habitat evaluation model: A case study of Seoul, Korea. Journal of the Korean Institute of Landscape Architecture 27(4): 29-38.

3. Chen, Y., X. Lehto and C. Liping(2013) Vacation and well-being: A study of Chinese tourists. Annals of Tourism Research 42: 284-310.

4. Diener, E., D. Wirtz, R. Biswas-Diener, W. Tov, C. Kim-Prieto, D. Choi and S. Oishi(2009) New measures of well-being. In E. Diener, ed., Social Indicators Research Series: Vol. 39. Assessing Well-being: The Collected Works of Ed Diener. New York, NY: Springer Science. pp. 247-266

5. Diener, E. and M. Seligman(2004) Beyond money: Toward an economy of well-being. Psychological Science in the Public Interest 5(1): $1-31$.

6. Diener, E.(1984) Subjective well-being. Psychological Bulletin 95(3) 542-575.

7. Diener, E.(1994) Assessing subjective well-being: Progress and opportunities. Social Indicators Research 31(2): 103-157.

8. Diener, E.(2000) Subjective well-being: The science of happiness and a proposal for a national index. American Psychologist 55(1): 34-43.

9. Diener, E.(2009) The science of well being: Reviews and theoretical articles. In E. Diener, ed., Social Indicators Research Series Vol. 37. The Science of Well Being: The Collected Works of Ed Diener. New York, NY: Springer Science. pp. 1-10.

10. Diener, E., E. Sandvik and W. Pavot(1991) Happiness is the frequency, not the intensity, of positive versus negative affect. In F. Strack, M. Argyle, and N. Schwarz, eds., Subjective Well-Being: An Interdisciplinary Perspective. New York, NY: Pergamon. pp. 119-139.
11. Diener, E., R. Emmons, R. Larsen and S. Griffin(1985b) The satisfaction with life scale. Journal of Personality Assessment 49(1): 71-75.

12. Diener, E., R. Larsen, S. Levine and E. Emmons(1985a) Frequency and intensity: The underlying dimensions of positive and negative affect. Journal of Personality and Social Psychology 48(5): 1253-1265.

13. Dolnicar, S., K. Lazarevski and V. Yanamandram(2013) Quality of life and tourism: A conceptual framework and novel segmentation base. Journal of Business Research 66(6) : 724-729.

14. Dolnicar, S., V. Yanamandram and K. Cliff(2012) The contribution of vacations to quality of life. Annals of Tourism Research 39(1): 59-83.

15. Dunn, E., D. Gilbert and T. Wilson(2011) If money doesn't make you happy, then you probably aren't spending it right. Journal of Consumer Psychology 21(2) : 115-125.

16. Eid, M. and E. Diener(2004) Global judgments of subjective wellbeing: Situational variability and long-term stability. Social Indicators Research 65(3): 245-277.

17. Frederick, S. and G. Loewenstein(1999) Hedonic adaptation. In D. Kahneman, E. Diener and N. Schwarz, eds., Well-Being: The Foundations of Hedonic Psychology. New York, NY: Russell Sage Foundation. pp. 302-329

18. Fredrickson, B.(1998) What good are positive emotions? Review of General Psychology 2(3): 300-319.

19. Grahn, P. and U. Stigsdotter(2003) Landscape planning and stress. Urban For Urban Green 2(1) : 1-18.

20. Gyeonggi Research Institute(2005) A Study on the Maximizing Efforts for Effective Use of Urban Forest. Gyeonggi Research Institute.

21. Hong, S., J. Kim, S. Jung and Y. Tae(2010) An economic valuation of arboretum using choice experiments. Journal of the Korean Institute of Landscape Architecture 37(6): 1-11.

22. Hong, S., K. An and H. Jang(2017) Interactional effects of travel experience and traumatic event on subjective well-being. Journal of the Korean Institute of Landscape Architecture 45(2): 1-10.

23. Hong, S., M. Lee, S. Lee and M. Ahn(2007) Searching for facilities and service programs for the establishment of urban park identification. Journal of the Korean Institute of Landscape Architecture 35(5): 29-36.

24. Jo, H. and T. Ahn(2006) Exploring relationships between urban tree plantings and microclimate amelioration. Journal of the Korean Institute of Landscape Architecture 34(5): 70-75.

25. Jo, H., J. Kim and H. Park(2016) Effects of pear orchards on carbon reduction. Journal of the American Pomological Society 70(2) : 63-73.

26. Kahneman, D. and A. Tversky(1979) Prospect theory: An analysis of decision under risk. Econometrica 47(2): 263-291.

27. Korea Forest Research Institute(2010) Quantification of Public Benefits of Forest. Research Report 10-26.

28. Korea Forest Service(2014) Statistics of Urban Forest. Korea Forest Service.

29. Korea Forest Service(2016) Statistics of Urban Forest. Korea Forest Service.

30. Kwon, H., W. Shin and J. Kim(2004) The comparison of use benefits based on types of urban forest. Korean Institute of Forest Recreation and Welfare 8(2): 37-46.

31. Lee, J., B. Park, Y. Tsunetsugu, T. Ohira, T. Kagawa and Y. Miyazaki (2011) Effect of forest bathing on physiological and psychological responses in young Japanese male subjects. Public Health 125(2): 93-100

32. Lien, J. and G. Buhyoff(1986) Extension of visual quality models for urban forests. Journal of Environmental Management 22(3): 245-254.

33. Loewe, N., M. Bagherzadeh, L. Araya-Castillo, C. Thieme and J. 
Batista-Foguet(2014) Life domain satisfactions as predictors of overall life satisfaction among workers: Evidence from Chile. Social Indicator Research 118(1): 71-86

34. Lucas, R., E. Diener and E. Suh(1996) Discriminant validity of wellbeing measures. Joumal of Personality and Social Psychology 71(3): 616-628.

35. Lyubomirsky, S., L, King and E. Diener(2005b) The benefits of frequent positive affect. Psychological Bulletin 131(6): 803-855

36. Lyubomirsky, S., K. Sheldon and D. Schkade(2005a) Pursuing happiness: The architecture of sustainable change. Review of General Psychology 9(2): 111-131.

37. Maas, J., R. Verheij, P. Groenewegen, S. de Vries and P. Spreeuwenberg(2006) Green space, urbanity, and health: How strong is the relation? Journal of Epidemiology \& Community Health 60(7) : 587592.

38. McCrae, R. and O. John (1992) An introduction to the five-factor model and its applications. Journal of Personality 60(2): 175-215.

39. Ministry of Cultures, Sports and Tourism(2016) 2016 Survey on National Leisure Activity. Ministry of Cultures, Sports and Tourism.

40. Ministry of Environment(2003) Design and Planning Criteria for the Green Buffer Zone. Ministry of Environment.

41. Oishi, S., E. Diener, E. Suh and R. Lucas(1999) Value as a moderator in subjective well-being. Journal of Personality 67(1): 157-184.

42. Pavot, W. and E. Diener(2008) The satisfaction with life scale and emerging construct of life satisfaction. Journal of Positive Psychology 3(2): 137-152.

43. Pavot, W., F. Fujita and E. Diener(1997) The relation between selfaspect congruence, personality, and subjective well-being. Personality and Individual Differences 22(2): 183-191.

44. Quoidbach, J., E. Berry, M. Hansenne and M. Mikolajczak(2010) Positive emotion regulation and well-being: Comparing the impact of eight savoring and dampening strategies. Personality and Individual Differences 49(5): 368-373.

45. Rusting, C. and R. Larsen(1997) Extraversion, Neuroticism, and sus- ceptibility to positive and negative affect: A test of two theoretical models. Personality and Individual Differences 22(5): 607-612

46. Shin, D. and D. Johnson(1978) Avowed happiness as an overall assessment of the quality of life. Social Indicators Research 5(1): 475492.

47. Shin, W., P. Yeoun, J. Lee, J. Lee and K. Kim(2010) The importantperformance analysis of urban recreational forests. Korean Institute of Forest Recreation and Welfare 14(1): 17-29.

48. Snyder, C. and S. Lopez(2002) Handbook of Positive Psychology. New York, NY: Oxford University Press.

49. Takano, T., K. Nakamura and M. Watanabe(2002) Urban residential environments and senior citizens' longevity in megacity areas: The importance of walkable green spaces. Journal of Epidemiology \& Community Health 56(12): 913-918

50. Tyrväinen, L., S. Pauleit, K. Seeland and S. de Vries(2005) Benefits and uses of urban forests and trees. In C. Konijendijk, K. Nilsson, T. Randrup, and J. Schipperijn, eds., Urban Forests and Trees. Berlin: Springer. pp. 81-114

51. Ulrich, R.(1984) View through a window may influence recovery from surgery. Science 224(4647): 420-421.

52. Wegener, D. and R. Petty(1994) Mood management across affective states: The hedonic contingency hypothesis. Journal of Personality and Social Psychology 66(6): 1034-1048.

53. Xiao, Q., E. McPherson, J. Simpson and S. Ustin(1998) Rainfall interception by Sacramento's urban forest. Journal of Arboriculture 24(4): 235-244.

54. Yardley, J. and R. Rice(1991) The relationship between mood and subjective well-being. Social Indicators Research 24(1): 101-111.

55. Yoo, R., K. Lee, S. Kim, S. Bae and E. Yoon(2007) A study on the preference analysis by use type of urban forests. Korean Institute of Forest Recreation and Welfare 11(4): 1-6.

56. http://kosis.kr/

57. http://www.saramin.co.kr

$\begin{array}{rlr}\text { Received : } 23 \text { March, } 2018 & \\ \text { Revised : } 07 \text { May, 2018 } & \text { (1st) } \\ & 09 \text { June, } 2018 & \text { (2nd) } \\ & 19 \text { June, } 2018 & \text { (3rd) } \\ \text { Accepted : } 19 \text { June, 2018 } & \\ \text { 3인익명 심사필 } & \end{array}$

